eomponents containing sulphur which could contribute to the radioprotective fraction of the extract.

This work was supported by a US Atomic Energy Commission contract. We thank Mrs Marion Spencer for technical assistance.

R. W. SERIANNI*

Department of Biology,

A. K. Bruev

State University of New York,

Buffalo, New York.

Received February $29,1968$.

* Present address: Chester Beatty Researeh Institute, clifton Avenue, Beimont, Sutton, Surrey.

' Bruce, A. K., Radiat. Res., 22, 155 (1964).

"Anderson, A. W., Raj, H. D., Wang, C. H., Duryee, F. L., and Elliker, P. R., Bact. I'roce, 12, 20 (1959).

Raj, H. D., Duryee, F. L., Deeney, A. M., Wang, (. H.. Anderson, A. W. and Elliker, P. R., Canad. J. Microbiol., 6, 289 (1960).

'Alexander, P., Lett, J. T., and Dean, C. J., Prog. Biochem. Pharmacol., 1, 22 (Karger, Basel, and New York, 1965)."

Balabukha, U. S., Chemical Protection of the Body Against Ionizing Radiation (Pergamon Press, London, 1963).

- Thomson, J. F., Radiation Protection in Mammals (Reinhold, New York 1962).

' Koltz, I. M., and Carver, B. R., Arch. Biochem. Biophys, 95, 540 (1961).

\section{Species of Borrelia from a Colombian Bat (Natalus tumidirostris)}

Although recurrent and relapsing fevers occur in Colom bia, the aetiological agents are seldom diagnosed. From Colombia only two of the six recognized forms of arthropodborne relapsing fevers have been reported: epidemic cosmopolitan relapsing fever caused by Borrelia recurrentis (synonyms $B$. obermeiri, $B$. novyi) and transmitted by lice (Pediculus humanus), and the endemic central and South American form of relapsing fever caused by $B$, venezuel ensis (synonym B. neotropicalis) transmitted in nature to man, monkeys and marsupials by the soft ticks (Ornitho. doros rudis, O.talaje, O.turcicate, O. rostrata and O. megnini). During the past $10 \mathrm{yr}$ no arthropod-borne relapsing fevers have been reported from Colombia but there have been several suspicious cases in the department of Santander, where $O$. rudis is not uncommon ${ }^{8}$.

Although no Colombian animals have been reported to harbour borrelias, we made a survey of the blood parasites of the bats in the department of Santander as part of a general survey of zoonotic disease.

Thick drop blood preparations of 2,986 Colombian bats pertaining to fifty-four species were examined, of which 512 individuals (five species) originated from the Macaregua cave in Santander. The blood preparations obtained hy cardiac puncture were air-dried for $24 \mathrm{~h}$. dehaemoglobinized, fixed with methanol, stained with Giemsa and examined at a magnification of approximately $\times 600$ for at least $12 \mathrm{~min}$. One of the thirty-four blood preparations made from the bat species Natalus tumidirostris showed an abundant infection with a species of Borrelia (Fig. 1). The bats were caught in the large Macaregua cave near San Gil which was inhabited by the following species: Mormoops megalophylla, Carrollia perspicillata. leptonycteris nivalis, Natalus tumidirostris and Desmodus rotundus.

Argasid ticks (Antricola mexicanus) which were prosent in large numbers in Macaregua cave wero examined by the following methods. Extension smears of 100 ticks were made and stained with Giemsa. Twenty CFW juvenile mice, five hamsters and two guinea-pigs were inoculated with material prepared from twelve macerated ticks each. Both the smears of the ticks and the blood of the inoculated laboratory animals were examined for the presence of borrelias. The peripheral blood of the inoculated mice was examined every 3 days for 21 days by the methods described. None of the 424 soft ticks examined by direct (smear) or the indirect (animal inoculation) methods revealed the presence of borrelias. The interior of the cave and the 512 bats collected there were thoroughly

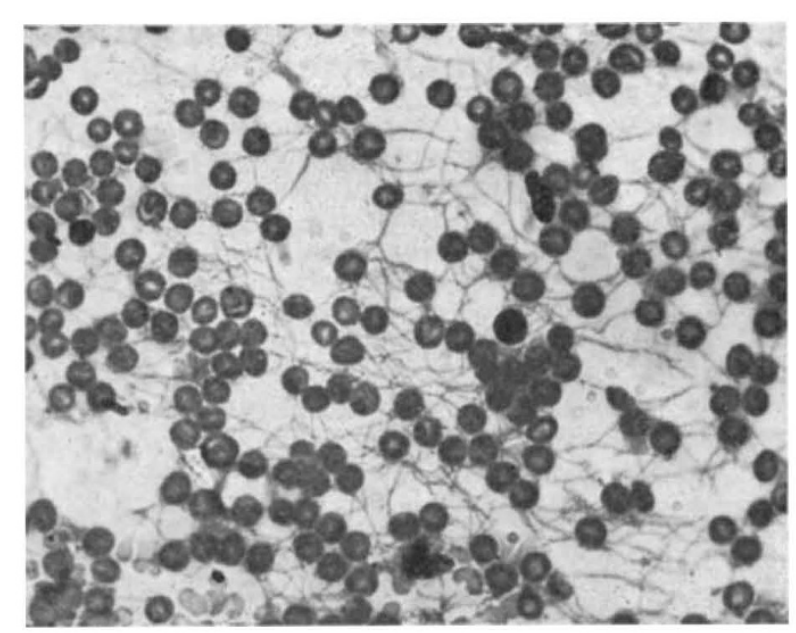

Fig. 1. Borrelia sp. in blood of Natalus tumidirostris. ( $\times$ c. 570.)

examined for the presence of arthropods, but no argasid ticks other than the common $A$. mexicanus and twelve Ornithodoros brodyi were found.

Because only the blood slides of one Natalus bat showed the presence of borrelias, no specific identification can be given. Nearly all species of Borrelia are indistinguishable because of their variability in morphology $y^{3,4}$ and difference in virulence for laboratory animals ${ }^{5}$, but they can sometimes be differentiated by their biological behaviour ${ }^{1}$. Serological methods for specific identification have been widely used, but their value has still to be proved ${ }^{1}$.

Only $B$. recurrentis, $B$. venezuelensis and $B$. turicata have been reported respectively from man and other mammals in the western hemisphere; while $B$. duttoni, $B$. hispanica and $B$. persica are only known from men in the eastern hemisphere, and B. tillae, B. normandi, $B$. cociduras, B. dipodelli (Spirochaeta dipodelli) and $S$. megadermae from mammals of Africa ${ }^{1,5,6,9}$.

A heavy blood infection in a single Colombian bat is interesting because only one other record of a bat infected with a blood spirochaete ( $S$. megadermae) has beon reported, and that from Africa ${ }^{7}$, and because heavy blood infections only occasionally exist in human infections with $B$. duttoni and in rats infected with $B$. tillae $e^{2,10}$. Neither B. duttoni or B. tillae, however, have been reported from the Americas.

The fact that only one bat out of the 512 examined from the cave was found to be infected, and none of the ticks from the same cave harboured borrelias, and that tickborne relapsing fever quite probably exists in the humarx population of the area, suggests that the bat became accidentally infected with the borrelia.

This work was supported in part by a grant from the US Army. We thank Dr C. O. Handley for identifying the bats, Dr G. M. Kohls for identifying the ticks, and Mr Leopoldo Rueda for allowing us to obtain the bats from Macaregua cave.

C. J. Marinketili: E. S. CRose

Departments of Biology and Microbiology.

Universidad de los Andos,

Bogotá, Colombia.

Received March 1, 1968.

${ }^{1}$ Geigy, R., and Aeschlimann, A., Rev. Suiss' Zoologie, 72, 87 (1965).

"Geigy, R., Mooser, H., and Weyer, F., Actr. Trop., 13, 193 (1956).

${ }^{3}$ Geigy, R., and Sarasin, G.. Acta Trop..18, 359 (1961).

1 Geigy, R., and Sarasin, (1.. P'athol. Microbiol., 24, 93 (1961).

'Heisch, R. B., E. African Med. .T., 27, 1 (1950).

'Heisch, R. B., Ann. Trop. Med. Parasit., 44, 260 (1950).

'Heisch, R. B., E. African Med. J., 29, 327 (1952).

${ }^{8}$ Osorno Mesa, E., Rev. Fae. Nuc. Agronom. (Medellin), 16-17, 1 (1942).

'Zumpt, F., Kongresses für Entomologie, Vienna, 3, 107 (1960).

${ }_{10}$ Zumpt, F., and Organ, D., South African J. Lab. Clin. Med., 7, 31 (1961). 